\title{
The Innovative Development Strategy of Service Trade in Wuhan Based on SWOT Analysis In the Context of Sino-US Trade Friction and The COVID-19 Pandemic
}

\author{
Hongping Wang ${ }^{1, \mathrm{a}}$, Fang Gao*2,b, Quanhong $\mathrm{Liu}^{3, \mathrm{c}}$, Yufan $\mathrm{Li}^{4, \mathrm{~d}}$ \\ ${ }^{1}$ School of Business, Jianghan University, Wuhan, China \\ ${ }^{2}$ School of Business, Jianghan University, Wuhan, China \\ ${ }^{3}$ School of Business, Jianghan University, Wuhan, China \\ ${ }^{4}$ School of Business, Jianghan University, Wuhan, China
}

\begin{abstract}
The negative impact of Sino-US trade friction on China and Wuhan's economy, politics, trade and many other fields is extensive and profound, and the COVID-19's outbreak has exacerbated this impact. Under these circumstances, this paper analyzes the strategic situation of Wuhan's service trade based on SWOT analysis. Accordingly, this paper puts forward countermeasures for the innovative development of service trade in Wuhan.
\end{abstract}

\section{Introduction}

The United States used to be one of China's largest exporters. The volume of trade in goods has increased from 2.5 billion dollars in 1979 to 633.5 billion dollars in 2018 , and the volume of trade in services has exceeded 125 billion dollars. With the gradual escalation of Sino-US trade friction, by 2019, China's import and export of service trade to the United States will drop to 3.73 trillion yuan, a year-on-year decrease of $14.6 \%$, showing a significant downward trend. In the same year, ASEAN replaced the United States as China's second largest trading partner. As of October 2020, ASEAN has become China's largest trading partner.

According to the COVID-19 pandemic, the import and export of services in China both showed a downward trend in January and February 2020. The total import and export volume of services was 740.31 billion yuan, a year-onyear decrease of $11.6 \%$. Wuhan, as the worst hit area of the pandemic, has also been hit by its trade in services. However, due to the timely control of the pandemic, in the first half of 2020, Wuhan's total import and export volume reached 103.790 billion yuan, a year-on-year increase of $3.1 \%$, and turned negative to positive from a decrease of $16.1 \%$ in the first quarter.

The Sino-US trade friction and the COVID-19 pandemic have brought about a great impact on the development of Wuhan's import and export trade, but it has been gradually restored to normal. It is of great significant to study the specific strategic situation of turning the crisis into safety. On the basis of this event, we find advantages, deal with weaknesses, seize opportunities and transform threats, which are of certain value to the development of service trade in Wuhan. Based on the above analysis, this paper puts forward some countermeasures for the innovation and development of service trade.

\section{The Strategic Situation of Service Trade in The Context of Sino-US Trade Friction and COVID-19 Pandemic}

\subsection{Analysis on the current strengths of service trade}

\subsubsection{China's current strengths in the field of service trade.}

China is the world's second largest economy, the largest manufacturing country, the largest trade in goods, the largest foreign exchange reserves. The super large-scale market advantage and domestic demand potential determine that China's economic operation is more resilient, has room to absorb external shocks, and has the ability to reduce the impact intensity through internal apportionment [1].

Since the outbreak of COVID-19, in China, due to effective prevention and control measures, the pandemic spread momentum has been effectively curbed, and the prevention and control situation has gradually improved. It's in the forefront of the world in pandemic control and resumption of production. 


\subsubsection{The current strengths of Wuhan in the field of service trade}

\subsubsection{Service outsourcing pilot successfully boosts} service trade. Since Wuhan has become a pilot city of service outsourcing in China, the scale of service trade has shown a rapid growth trend. During the pilot period, Wuhan's total service import and export grew by more than $30 \%$ annually. In 2018 , the total value of service import and export reached 10.106 billion dollars, of which 2.206 billion dollars. The development scale of service trade ranked first in Central China.

At present, Wuhan's service outsourcing industry has made great progress, which has provided strong support for promoting green development and high-quality development, and has become a new driving force for the transformation and upgrading of service industry and a new engine for the development of open economy.

\subsubsection{The comprehensive ability of digital culture is} in the forefront of the country. With the popularity of the Internet and digital technology, China's digital culture industry has developed rapidly. Digital culture has become the mainstream form of mass culture consumption and information consumption, which has a profound impact on their way of life, social way and expression. In recent years, Wuhan's trade in personal, cultural and entertainment services have shown an upward trend in terms of import, export and total trade volume.

According to the "Digital China Index report 2019" released by Tencent Research Institute, Wuhan's digital culture index ranks among the top ten cities in China in the fields of news, video, literature, animation, film, music and games. It can be seen that Wuhan's development ability and prospects are better. With high digital culture index and good user base, it will be the bridgehead for the development of digital cultural products in Wuhan.

\subsubsection{COVID-19 prevention and control experience} is leading the world. COVID-19's outbreaks in China are one of the earliest outbreaks in China. Wuhan is the central city of the pandemic in China. As of April 30, 2020, the existing confirmed cases, suspected cases and new cases in Wuhan have all returned to zero, and the occasional new cases imported from abroad are not enough. To some extent, COVID-19 was under control in China, and Wuhan's experience in the prevention and control of diseases is leading the world.

With the global spread and worsening of the pandemic situation, Wuhan has absolute advantages in many service trades, such as pandemic prevention services, prevention and control experience output, prevention and control materials output and post pandemic reconstruction service experience output. Its associated supporting materials and service provision have broad international market prospects and trade opportunities.

\subsection{Analysis of the current weaknesses in the field of service trade}

\subsubsection{China's current weaknesses in the field of service trade.}

In the context of the continuous development of global service trade and digital technology, China's service trade has shown a strong growth momentum in recent years, which has played an important role in optimizing the trade structure and promoting employment. However, the proportion of China's service trade in GDP is still far behind that of developed countries. According to the world trade report 2019 issued by WTO, the average proportion of world service trade in GDP is $13 \%$, that of high-income countries is $15 \%$, that of low-income countries is $8 \%$, and that of China is only $6 \%$.

Moreover, the structure of China's service trade is not balanced, and it has a great weakness in the emerging industries and technology fields. For many years, traditional industries such as transportation and travel have been the development pillars of China's service trade. In 2019, the import and export of these two industries will account for $58.7 \%$. But in the financial services, information services, patent technology and other technology intensive service trade, China's export growth is slow [2].

\subsubsection{The current weaknesses of Wuhan in the field of service trade}

2.2.2.1 The lack of openness leads to low dependence on foreign trade. Wuhan has a large population and rich resources. However, restricted by various conditions, the degree of opening to the outside world and the dependence on foreign trade are relatively low. Although the import and export volume has been showing an increasing trend in recent years, its proportion in the national import and export volume in the same period has not increased significantly. Therefore, it is necessary to further expand the degree of opening up and increase the degree of dependence on foreign trade.

\subsubsection{As a new engine of development, service outsourcing is still at the low end of the industrial chain. At present, Wuhan's service outsourcing industry has made great progress in the development scale, number of enterprises, number of employees, technological progress, etc., but the current service structure is more inclined to the low-end industrial chain. In the field of information technology, pharmaceutical research, management consulting and other service outsourcing business, the promotion of high-end and international development of service outsourcing is relatively lagging behind. This development trend obviously cannot keep up with the development pace of $5 \mathrm{G}$ information age.}


2.2.2.3 Service trade talents are relatively scarce. Talent is the most important resource of economic and social development, the foundation of urban competition, the key of kinetic energy conversion and the source of innovation vitality. Wuhan has 89 colleges and universities of all kinds, with 1.3 million college students, ranking among the top cities in the world, so it does have advantages in human resources. However, as a new first tier city, due to the lack of urban development level, the limited degree of internationalization and the low level of salary and welfare, Wuhan is relatively less attractive to talents. According to the "Research Report on China's Urban Vitality in 2019" released by Baidu Map, Wuhan's population attractiveness index is only 4.196 among the 100 major cities in China, ranking 12th even after Chengdu, Chongqing, Zhengzhou and other central and western cities. Generally speaking, there are human resources limitations in many fields in Wuhan, and the talents of service trade are relatively scarce.

\subsection{Analysis of the current opportunities in the field of service trade}

\subsubsection{The current opportunities in the field of service trade in China.}

According to the "Business Environment Report in 2020" issued by the World Bank, China's state-owned business environment ranked in 190 economies in the world, which rose 15 in 2019 to 31 st in the world after a significant 32digit increase in 2018. It is generally accepted by all walks of life abroad that in recent years, the environment of state-owned business has improved significantly, which has stimulated the endogenous power of economic development, and China has become an increasingly attractive investment destination in the world [3]. Meanwhile, the Belt and Road Initiative could provide broad space for infrastructure construction, employment and market development, and attract more famous international enterprises to invest in China. In recent years, the proportion of added value of service industry in China to GDP has exceeded $52 \%$. In the future, it will continue to improve, and service trade will continue to develop healthily. Meanwhile, the growth of service outsourcing will promote the upgrading of service trade structure, which is conducive to seize the market opportunity.

\subsubsection{The current opportunities in the field of service trade in Wuhan}

\subsubsection{A significant improvement in the business} environment is conducive to enhancing market trust. Recently, the competition in the international market has become increasingly fierce, and countries all over the world attach great importance to the improvement of business environment. According to the "China Urban Business Environment Report in 2019", the ranking of business environment in Wuhan has risen from 16th to 6th, and the business environment index has risen from 70.4 to 81.66. Among them, the hard environment index ranked fifth and the soft environment index ranked seventh. The improvement of business environment is conducive to enhancing market trust and providing new opportunities for the development of service trade in Wuhan.

\subsubsection{2 " The Belt and Road Initiative" node city} ushering in new international market space. " The Belt and Road Initiative" has provided new impetus and market space for the development of China's service outsourcing industry, providing support for the sustainable development and complementary development of China's service outsourcing industry. As a node city, " The Belt and Road Initiative" has expanded the new market of Wuhan's service outsourcing market.

\subsubsection{High quality development of Yangtze River} Economic Belt produces radiation effect. The Yangtze River Economic Belt has formed a service outsourcing industry pattern with Shanghai, Jiangsu, Zhejiang and other Yangtze River Delta regions as the leaders, driving the rapid development of provinces and cities in the middle and upper reaches of the Yangtze River. It is expected to promote the development of service outsourcing industry in Wuhan by giving play to the agglomeration effect and radiation demonstration effect of service outsourcing industry in Yangtze River Economic Belt.

\subsection{Analysis of the current threats in the field of service trade}

\subsubsection{The current threats in the field of service trade in China.}

As a new business, service outsourcing business in China has been rising rapidly, but it also faces many challenges. The competition of global service outsourcing industry is intensified, Sino-US trade friction is upgrading, unilateralism and protectionism are intensified, international order and multilateral trading system are seriously impacted, which has brought negative impact on global trade and investment [4].

Affected by the COVID-19 pandemic, with the upgrading of pandemic prevention and control and traffic control, many products were short of production reserves and supply was broken. This has great impact on the global supply chain, and the impact resistance ability of SMEs is usually weak, resulting in multiple industry chain breakage and uncertain factors [5].

\subsubsection{The current threats in the field of service trade in Wuhan}

2.4.2.1 Lack of impetus for the development of traditional service trade industry. According to the data (Table 1), from January to September in 2019, the import and export volume of three traditional services of travel, transportation and construction in Wuhan were respectively 6742.3026 million dollars, 162.2717 million 
dollars and 254.9871 million dollars, with a total of 7159.5614 million dollars, a year-on-year decrease of $5.33 \%$. Among them, the most obvious decline was in transport trade, with the year-on-year decreases of import and export volume reaching $20.45 \%, 38.33 \%$ and $28.77 \%$ respectively. According to the data of Wuhan Tourism Administration in the third quarter, the number of visitors to Hong Kong, Macao and Taiwan decreased by about 200,000 over the same period, making the overall situation of tourism decline. The second was construction services, with a year-on-year decrease of $34.28 \%$ in import and export. In terms of travel, imports decreased by $8.77 \%$, exports increased by $38.33 \%$, and total trade volume decreased by $3.94 \%$. In addition, the maintenance and repair services in Wuhan also decreased significantly, with the import and export volume and total trade volume falling by $20.90 \%, 21.63 \%$ and $21.38 \%$ respectively.

Table1. Annual Statistics of Traditional Wuhan Service Trade in Recent Three Years (Million Dollars)

\begin{tabular}{|c|c|c|c|c|c|c|c|}
\hline \multicolumn{2}{|c|}{ Industry } & Transportation & Tourism & Construction & $\begin{array}{c}\text { Insurance } \\
\text { services }\end{array}$ & $\begin{array}{c}\text { Financial } \\
\text { service }\end{array}$ & Technology \\
\hline \multirow{3}{*}{$\mathbf{2 0 1 7}$} & Import & 284.14 & 5545.00 & 456.79 & 11.25 & 104.24 & 554.92 \\
\cline { 2 - 8 } & Export & 94.35 & 2157.04 & 477.10 & 95.70 & 2.28 & 75.65 \\
\cline { 2 - 8 } & Total & 378.50 & 7702.05 & 933.89 & 106.95 & 106.52 & 630.57 \\
\hline \multirow{3}{*}{$\mathbf{2 0 1 8}$} & Import & 157.91 & 5754.53 & 358.27 & 12.43 & 296.86 & 373.22 \\
\cline { 2 - 8 } & Export & 128.60 & 2922.42 & 261.36 & 94.15 & 20.44 & 158.64 \\
\cline { 2 - 8 } & Total & 286.51 & 8676.95 & 619.63 & 106.58 & 317.30 & 531.87 \\
\hline \multirow{3}{*}{$\mathbf{2 0 1 9}$} & Import & 129.26 & 5387.45 & 158.43 & 9.37 & 322.21 & 333.05 \\
\cline { 2 - 8 } & Export & 87.11 & 3602.28 & 181.55 & 10.05 & 12.87 & 169.01 \\
\cline { 2 - 8 } & Total & 216.36 & 8989.74 & 339.98 & 19.41 & 335.07 & 502.06 \\
\hline
\end{tabular}

Data Resources: Wuhan Municipal Bureau of Commerce

\subsubsection{The uneven distribution of cooperation leads to limited market expansion space. At present, the distribution of service trade countries and regions in Wuhan is uneven. The countries and regions that trade with Wuhan mainly come from Asia, North America and Europe. The main export destinations of Wuhan's service trade are Hong Kong, Europe and the United States, which account for about $60 \%$ of the total export volume. The import sources of Wuhan's service trade are mainly Japan, Hong Kong and Europe, which account for about $80 \%$ of the total import volume. Therefore, in order to promote the comprehensive development of service trade, we must expand a broader overseas market.}

\subsubsection{As the center of the pandemic may induce a} crisis of trust. As a center city of COVID-19 pandemic, Wuhan had become one of the most famous cities in the world. Its negative effects are manifold. First of all, Wuhan is the slowest city in the country to resume production and work, which greatly affects the performance ability of Wuhan's service trade; second, Customers may not have enough confidence in the realization of trade normalization of Wuhan enterprises, which may also cause existing customers to interrupt the follow-up trade with Wuhan enterprises and seek other instead.

\section{Innovative development strategy of service trade in Wuhan}

In view of the current situation and strategic situation of Wuhan, the following strategies can be taken:

\subsection{Optimize the spatial distribution of service trade}

At present, the distribution of service trade countries and regions in Wuhan is uneven. The countries and regions that trade with Wuhan mainly come from Asia, North America and Europe. Therefore, in order to promote the overall development of service trade, we must first expand a wider overseas market, especially in order to reduce the adverse effects of Sino-US trade friction, and change the current situation of over dependence on the U.S. market.

China's "the Belt and Road Initiative" has achieved remarkable results in recent years. The service trade volume of node cities continues to grow. Therefore, Wuhan should seize the opportunities and increase the trade intensity to the relevant cooperative countries.

\section{2 conduct service trade with the United States in accordance with the situation}

The data shows that Wuhan has been relying too much on the United States in the field of service trade in recent years. In terms of import, the United States is the fourth largest import source of Wuhan service trade. In the past three years, the import volume to the United States reached 267.8292 million dollars, 28.1688 million dollars and 458.558 million dollars respectively. The year-on-year growth in 2019 reached $22.09 \%$. In terms of export, the United States is the fourth largest export destination of Wuhan service trade. The export volume to the United States in recent three years reached 110.9755 million dollars, 137.2638 million dollars and 148.265 million 
dollars respectively, of which, the year-on-year growth in 2019 reached $8.01 \%$. This also shows that, even in the situation of tight bilateral economic and trade relations between China and the United States, on the one hand, Wuhan has strong competitiveness in some service fields, such as service outsourcing, etc.; on the other hand, Wuhan has a new demand for the U.S. market in some service fields, such as the technology urgently needed to promote the upgrading of industry. Therefore, Wuhan should take advantage of the situation, overcome the adverse effects and carry out trade with the United States reasonably.

\subsection{Vigorously support small and medium-sized enterprises to overcome difficulties}

Small and medium-sized enterprises and private enterprises are an important part of China's service trade, accounting for more than $50 \%$ of trade exports. However, it has been in a weak position in China's economic structure for a long time [6]. In the context of COVID-19 pandemic, these enterprises in Wuhan are even more difficult. They are facing the weaknesses of lagging back to work, tight capital, fragile value chain and single trade structure. Therefore, we should strengthen the support for small and medium-sized enterprises and private enterprises, introduce preferential tax and social security policies, reduce the cost of water and electricity, simplify the procedures, and extend the tax declaration period.

\subsection{Optimize the talent structure of service trade}

In the aspect of service trade talent optimization, in addition to policy support, Wuhan should adopt a more flexible way to actively establish various talent platforms, such as talent exchange platform, talent introduction platform, talent training platform, especially the training platform for innovative talents, and use these platforms to introduce and cultivate advanced talents [7]. At the same time, we should adopt more flexible preferential policies to create a good environment that can attract, encourage domestic and foreign advanced technical personnel to invest and start businesses in Wuhan.

\section{Conclusion}

The COVID-19 pandemic and Sino-US trade friction have a great impact on the development of service trade in China and Wuhan. This paper analyzes the strategic situation of Wuhan's service trade in this context. We draw a conclusion that in the context of COVID-19 pandemic and Sino-US trade fraction the development of service trade in Wuhan is mixed. But in general, the strengths are stronger than weaknesses, and opportunities are more than threats, and their long-term development momentum will not change. The exploration of innovative development strategy in this paper may be conducive to the development of Wuhan service trade and reach to a new height.

\section{Acknowledgment}

This paper is supported by the Graduate Students Research Innovation Fund of Jianghan University.

\section{References}

1. F. Zhu, S. Zhao, "Sino-US trade friction and China's trade power construction", China Circulation Economy, 2019,33(03): 82-90.

2. Y. $\mathrm{Wu}$, "Research on China's service trade response and financial policy improvement under Sino US trade friction", Financial theory and practice, 2018 (11): 56-62.

3. Q. Guo and W, Chen, "Impact of Sino US trade friction on China's international trade and countermeasures", Comparison of economic and social systems, 2019 (05): 78-90.

4. G. Shen, "The dilemma and relief measures of promoting domestic and international double circulation and promoting economic and Trade Development under the global epidemic situation", Journal of Chongqing University (SOCIAL SCIENCE EDITION), 2021,27 (01): 1-13.

5. C. Yang, "COVID-19 and Sino-US trade frictions under the double impact of Sichuan's foreign trade enterprises to promote the process of globalization" , Economic Forum, 2021 (01): 65-73.

6. Y. Xue, F. Jin, J. Li, "Evolution and influence of SinoUS trade relations and China's enterprises' response", Macro Quality Research, 2020,8 (01): 1-18.

7. L. Lang, "The causes, effects, and policy suggestions of Sino-US trade imbalance", Economic and Management Research, 2006, (07): 31-34; 49. 